ISAHP Article: Bahurmoz/Integrating the AHP Methodology into the Procedures of Decision Making in Governmental Agencies. To Be Submitted to the International Symposium of the Analytic Hierarchy Process 2014, Washington D.C., U.S.A.

\title{
INTEGRATING THE ANALYTIC HIERARCHY PROCESS METHODOLOGY INTO THE PROCEDURES OF DECISION MAKING IN GOVERNMENTAL AGENCIES.
}

\author{
Asma M. Bahurmoz \\ Department of Business \\ King Abdulaziz University \\ E-mail: asma@bahurmoz.com
}

\begin{abstract}
The Gulf Cooperation Council Countries are challenged by unprecedented labor problems. These countries suffer from unemployment problems in spite of the fact that they offer jobs for millions of immigrants. Non indigenous fill $95 \%$ of the private sector jobs in these countries. Saudi Arabia as the largest country in terms of area and population suffers the most from this unemployment problem. In cooperation with the ministry of Labor, executive MBA(EMBA) students from $\mathrm{KAU}$ focused on a number of these problems, defined them, explored solutions and prioritized these solutions from the point of view of officials in the ministry, employers and job seekers. The Analytic Hierarchy Process was chosen as the methodology to help the decision makers in the ministry decide on which strategy to take to address these problems.

The objective is to promote the use of AHP in the process of governmental decision making by introducing it via the activity of Service Learning
\end{abstract}

Keywords: Service Learning, AHP, MCDM, Group decision making, Public Agencies.

\section{Introduction}

Officials in the Legislation and policy making agents are faced by many problems which they have to solve. Most of these problems are complex, and require urgent decisions. These decisions are important as their outcome affects the wellbeing of a nation as whole, and consequently it influences the country's political stability. Therefore, decision makers need the help of scientific tools to rationalize their decisions. Such tools have to be easy to learn and use with the minimum of data requirements. To serve such need the Analytic Hierarchy Process is proposed as a handy tool scientific and robust for multi criteria decision making process. In spite of the fact that the AHP methodology has been a well known multi criteria decision tool and hundreds of academic papers are published in many recognized journals and in many different languages, its adaptation and integration into the day to day process of decision making practice is still less than expected. In an 
ISAHP Article: Bahurmoz/Integrating AHP Methodology Into the Procedures of Decision Making in Governmental Agencies. To Be Submitted to the International Symposium of the Analytic Hierarchy Process 2014, Washington D.C., U.S.A.

effort towards bridging this gap, I present a case where the teaching of the AHP is taking a step out of the lecture room and into the local community. The AHP is implemented as a tool for the service learning methodology for the quantitative methods course taken by the EMBA students at the business department of King Abdulaziz University.

The intention is to help students implement their analytical skills in serving their communities and getting the decision makers in the community to feel the essence of help that can be obtained by adopting decision making tools such as the AHP. In collaboration with the ministry of Labor (MOL), students examined problems facing the labor market, a few problems were selected to be studied and alternative solutions were proposed and prioritized implementing the AHP. The goal is to demonstrate the applicability and usability of MCDM tools in the public sector to help shaping the strategy of its services

\section{Literature Review:}

The AHP methodology is well known and well documented in the literature, to name only a few (Saaty, 2008, 2011\& 2012), Saaty, T.L., \& Peniwati, K. (2007). Not to mention the translation or documentation of many of the reference works into several languages. Also, Service Learning is a well known teaching methodology (Bellner\&Promery, 2005). However, very few cases are reported and documented in literature (Tilleman, et.al. 2012) and mostly in the medical and related disciplines such as nursing and nutrition specialty. Search reveals no publications for using of the AHP as a tool in the service learning activity. On the other hand there is relative scarcity in applying the AHP in the area of labor market problems or in public agencies as a whole.

\section{Hypotheses/Objectives}

The main objective of this research is to help integrate the AHP methodology into the process of decision making in the public sector. This is to be achieved via educating its officials by having the students implementing it to analyze problems or issues nagging decision makers in these organizations.

Such initiative will help them to understand how the AHP methodology can be used as a decision making tool in the problem solving process and in strategy shaping in public sector organizations.

\section{Research Design/Methodology}


ISAHP Article: Bahurmoz/Integrating AHP Methodology Into the Procedures of Decision Making in Governmental Agencies. To Be Submitted to the International Symposium of the Analytic Hierarchy Process 2014, Washington D.C., U.S.A.

This research was carried in collaboration with the ministry of Labor in Saudi Arabia via their initiative of supporting the "Service Learning" methodology in teaching. Service learning (Bellner\& Promery 2005) is a well known concept where students and their teachers are required to explore the community around them and practice what they learn in class in an attempt to help their community with the knowledge they learnt and teach students the importance of directing their knowledge towards serving their own communities.

The service learning methodology was implemented as follows:

1 - Students learn the AHP in class.

2- Instructor coordinates with MOL officials for a meeting with the whole class.

3- A presentation is given which highlights complicated problems challenging the labor market and for which MOL is seeking solutions.

4- Students are divided into small teams (5-7 students). Each team selects one problem to address.

4- Research is conducted using resources available on MOL's website as well as other involved agencies, surveys or interviews.

5- Students work collaboratively with concerned decision makers in structuring the problem into an AHP hierarchy and elicit the judgments from the concerned expert officials in addition to other stakeholders if the nature of the problem requires so.

6- A short report is submitted by every team identifying the problem, the goal expected and what criteria should a good policy have and suggesting a set of policy alternatives.

7- A short presentation is given by every team in the presence of the MOL officials, who will evaluate and provide feedback on the models designed by the students.

\section{Data/Model Analysis}

Students defined several issues that are at the root of unemployment of youth and focus on the following four problems to be studied:

1- Illegal labor which is a disturbing phenomena in the Saudi labor market and challenging variety of policies due to its sensitivity from human and religious point of view.

2- How to increase female participation in the labor market,

3- What is the best alternative to extend the labor supporting fund's services to outreach remote communities?

4-- How to attract locals to take vocational jobs.

Each problem was structured in a hierarchy form: at its top is the goal followed by the criteria and the sub criteria required to be achieved and the bottom of the hierarchy are the alternatives. The AHP solution to each of the above problems was conducted with the MOL experts. The students' team played the role of the 
ISAHP Article: Bahurmoz/Integrating AHP Methodology Into the Procedures of Decision Making in Governmental Agencies. To Be Submitted to the International Symposium of the Analytic Hierarchy Process 2014, Washington D.C., U.S.A.

facilitator in the setting of group decision making. For illustration, Figures 1 , 2, $\& 3$ illustrate the analysis of the last problem. (Problem no 4) figure 1 represents the hierarchy and the local priorities for each criterion, also shows the alternatives and their priorities. Figures $2 \& 3$ illustrate the matrices of pair comparison of the main criteria and the alternatives.

\section{Figure 1: The hierarchy of nationalizing vocational jobs.}

I reeview

\begin{tabular}{|c|c|}
\hline \multicolumn{2}{|l|}{ Goal: Saudization Vocational Jobs } \\
\hline \multicolumn{2}{|l|}{ Economic (L: .143) } \\
\hline \multicolumn{2}{|l|}{ Create jobs with economic income (L: .889) } \\
\hline \multicolumn{2}{|l|}{ Achieve suitable rates for Saudization (L: .111) } \\
\hline \multicolumn{2}{|l|}{ Education (L: .143) } \\
\hline \multicolumn{2}{|l|}{ Attract public schools students (L: .857) } \\
\hline \multicolumn{2}{|l|}{ Skilled labor trained \& specialized (L: .143) } \\
\hline \multicolumn{2}{|l|}{ Social (L: .714) } \\
\hline \multicolumn{2}{|l|}{ Attitudes \& Values (L: .167) } \\
\hline \multicolumn{2}{|l|}{ Social outlook for these jobs (L: .833) } \\
\hline \multicolumn{2}{|l|}{ Alternatives } \\
\hline Encourage entrepreneurship in vocational business & .033 \\
\hline $\begin{array}{l}\text { Make agreements between major companies and vocational training } \\
\text { institutions }\end{array}$ & .036 \\
\hline Issue professional licenses for vocational job \& training institutions & .068 \\
\hline Raise social awareness of the importance of vocational work & .320 \\
\hline Promote the values of responsibility \& commitment in work & .257 \\
\hline Extracurricular vocational activities in the secondary schools & .167 \\
\hline Transform vocational training programs to secondary schools & 099 \\
\hline Retrain job seekers by professional programs & .021 \\
\hline
\end{tabular}

Figure 2: Priorities with respect to Goal

\author{
Priorities with respect to: \\ Goal: Saudization Vocational J obs \\ Economic \\ Education \\ Social \\ Inconsistency $=\mathbf{0}$. \\ with 0 missing judgments.
}


ISAHP Article: Bahurmoz/Integrating AHP Methodology Into the Procedures of Decision Making in Governmental Agencies. To Be Submitted to the International Symposium of the Analytic Hierarchy Process 2014, Washington D.C., U.S.A.

Figure 3: Matrix of Pairwise comparisons of alternatives with respect to attitudes and values.

Compare the relative importance with respect to: Attitudes \& Values (L: .167)

\begin{tabular}{|c|c|c|c|c|c|c|c|c|c|c|c|c|c|c|c|c|c|c|c|}
\hline \multicolumn{2}{|r|}{1 = Equal } & \multicolumn{18}{|c|}{ Circle one number per row below using the scale: } \\
\hline 1 & Encourage entreprer & 9 & 8 & 7 & 6 & 5 & & 3 & 2 & 1 & 2 & & 4 & 5 & 6 & 7 & 8 & 9 & Make agreements be \\
\hline 2 & Encourage entreprer & 9 & 8 & 1 & 6 & 5 & 4 & 3 & 2 & 1 & 2 & J & 4 & J & 6 & r & 8 & $y$ & Issue professional lic \\
\hline 3 & Encourage entreprer & 9 & 8 & 7 & 6 & 5 & 4 & 3 & 2 & 1 & 2 & 3 & 4 & 5 & 6 & 7 & 8 & 9 & Raise social \\
\hline 4 & Encourage entreprer & 9 & 8 & 7 & 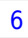 & - & & 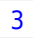 & 2 & 1 & 2 & & & 5 & 6 & 7 & 8 & 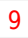 & es c \\
\hline 5 & Encourage entreprer & 9 & 8 & 7 & 6 & $J$ & 4 & 3 & 2 & 1 & 2 & 3 & r & J & 6 & ( & 8 & $y$ & ocat \\
\hline 6 & Encourage entreprer & 9 & 8 & 7 & 6 & 5 & 4 & 3 & 2 & 1 & 2 & 3 & $t$ & 5 & 6 & 7 & 8 & 9 & ona \\
\hline 7 & Encourage entreprer & J & 8 & 7 & r & 5 & 4 & 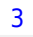 & 2 & 1 & $L^{2}+2$ & J & & & & & 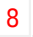 & 9 & t. \\
\hline 8 & Make agreements b€ & 9 & 8 & 7 & 6 & J & 4 & 3 & 2 & 1 & 2 & J & 4 & J & 0 & $t$ & 8 & 9 & sional lic \\
\hline 9 & Make agreeme & 9 & 8 & 7 & 6 & 5 & 4 & 3 & 2 & 1 & 2 & $3+2+3$ & & 5 & 6 & 7 & 8 & 9 & Rais \\
\hline 10 & 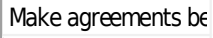 & 9 & 8 & 7 & 6 & J & 4 & J & 2 & 1 & 2 & J & & J & & 7 & & J & values c \\
\hline 11 & Make agreeme & 9 & 8 & $t$ & 6 & J & 4 & J & 2 & 1 & 2 & $J$ & 4 & J & 6 & 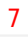 & 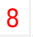 & $y$ & ocat \\
\hline 12 & Make agreements b€ & 9 & 8 & 7 & 6 & 5 & 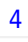 & 3 & 2 & 1 & 2 & 3 & & 5 & 6 & 7 & 8 & 9 & cationa \\
\hline 13 & $N$ & 9 & 8 & 7 & 6 & 5 & 4 & 3 & 2 & 1 & 2 & J & 4 & J & 6 & 7 & 0 & 9 & t \\
\hline 14 & Issue p & 9 & 8 & 7 & 0 & 3 & 4 & כ & 2 & 1 & 2 & J & 4 & 3 & b & $I$ & 0 & $y$ & arene \\
\hline 15 & Issue professional lic & 9 & 8 & 7 & 6 & 5 & 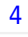 & 3 & 2 & 1 & $?$ & 3 & & 5 & ) & 7 & & 9 & values ( \\
\hline 16 & Issue pr & 9 & 8 & 7 & 6 & 5 & 4 & J & 2 & 1 & 2 & J & 4 & J & 6 & . & 0 & 9 & ar vocat \\
\hline 17 & Issue $p$ & 9 & 8 & 7 & 6 & כ & 4 & 3 & 2 & 1 & 2 & J & 4 & J & 6 & $I$ & 0 & 9 & ona \\
\hline 18 & Issue $p$ & 9 & 8 & 7 & 6 & 5 & 4 & 3 & 2 & 1 & 2 & 3 & 7 & 5 & 6 & 7 & & 9 & ers $k$ \\
\hline 19 & ane & 9 & 8 & 7 & 6 & 5 & T & 3 & 2 & 1 & $2+2$ & J & & s & 6 & $r$ & & 9 & SC \\
\hline 20 & Raise social awaren€ & 9 & 8 & 1 & 6 & 5 & 4 & 3 & 2 & 1 & 2 & 3 & 4 & 5 & 0 & $-7+2>$ & 8 & $y$ & lar vocat \\
\hline 21 & Raise social awaren€ & 9 & 8 & 7 & 6 & 5 & 4 & 3 & 2 & 1 & 2 & 3 & 4 & 5 & 6 & I & 8 & 9 & ocationa \\
\hline 22 & Raise social awaren€ & 9 & 8 & 7 & r & 5 & 4 & 3 & 2 & 1 & 2 & J & & J & 6 & r & & 9 & eekers $\mathrm{k}$ \\
\hline 23 & Promote & $y$ & 8 & $t$ & 6 & J & 4 & J & 2 & 1 & 2 & 0 & 4 & 0 & 6 & 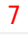 & 0 & $y$ & ir vocat \\
\hline 24 & Promote $t$ & 9 & 8 & 7 & 6 & 5 & $t$ & 3 & 2 & 1 & 2 & 3 & 4 & 5 & 6 & I & 8 & 9 & Transform \\
\hline 25 & Promote the values ( & 9 & 8 & 7 & 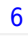 & - & . & 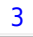 & 2 & \pm & 2 & J & 4 & 5 & 6 & 1 & 8 & 9 & seekers $\mathrm{k}$ \\
\hline 26 & Extracurricular vocat & 9 & 8 & 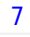 & 0 & 5 & 4 & 3 & 2 & 1 & 2 & 3 & 4 & 5 & 6 & 7 & 0 & $y$ & Transform vocationa \\
\hline 27 & Extracurricular vocat & 9 & 8 & 7 & 6 & 5 & 4 & 3 & 2 & 1 & 2 & 3 & 4 & 5 & 6 & 1 & 8 & 9 & Retrain job seekers $\mathrm{k}$ \\
\hline 28 & Transform vocationa & 9 & 8 & $t$ & 6 & 5 & 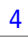 & 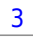 & 2 & 1 & 2 & 3 & 4 & 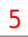 & 6 & 1 & 0 & J & Retrain job seekers \\
\hline
\end{tabular}

\section{Limitations}

The fact that this work is carried through one semester and as a term paper, made it difficult to achieve more thorough work and nalysis. However, one can say it delivered its purpose of exposing officials in MOL to the advantages of the AHP and motivate them to learn more. Meanwhile students gained confidence in the subject they are learning and strengthened their employability.

\section{Conclusions}

The analytic Hierarchy Process is used to analyze and prioritize different policy alternatives for the labor market focusing on increasing jobs' opportunities for the 
ISAHP Article: Bahurmoz/Integrating AHP Methodology Into the Procedures of Decision Making in Governmental Agencies. To Be Submitted to the International Symposium of the Analytic Hierarchy Process 2014, Washington D.C., U.S.A.

local community and exposing officials in the ministry of labor to the robustness of the methodology and simplicity of implementing it.

EMBA students enrolled in quantitative methods are directed to work collaboratively in conducting research towards problem solving and gain experience in solving real national problems implementing AHP and sharing their knowledge with decision makers who are in need to learn such methodologies.

\section{Key References}

Chemingui M \&Terry Roe (2008) Petroleum revenues in Gulf Cooperation Council countries and their labor market paradox. Journal of Policy Modeling 30, 491-503.

Bellner\& Promery (2005), Service-learning: Intercommunity \& Interdisciplinary Explorations. University of Indianapolis Press.

Tilleman, Jennifer Tilleman, PharmD, FASCPa, Kelli L. Coover, PharmD, CGP, FASCP ,Elaine Blythe, PharmDb,c, Joy Doll, OTD, OTR/La, Karen O'Brien, PharmDa,Ann Ryan Haddad, PharmDa( 2012) Service-learning incorporated into early practice experience. Currents in Pharmacy Teaching and Learning 4 , 292-297.

Saaty, T.L. (2012) Decision Making for Leaders: The Analytic Hierarchy Process for Decisions in a Complex World, Third Edition. Pittsburgh, PA: RWS Publications.

Saaty, T. L. (2011) On the Measurement of Intangibles. A Principal Eigenvector Approach to Relative Measurement Derived from Paired Comparisons, Notices of the AMS, 60:2, and 192-208.

Saaty, T. L. (2008). Decision making with the analytic hierarchy process, International Journal of Services Sciences, 1:1, 83-98.

Saaty, T.L., \& Peniwati, K. (2007). Group decision-making: Drawing out and reconciling differences. Pittsburgh, PA: RWS Publications. 